\title{
A Randomized Clinical Trial of the Effect of Intraoperative Saline Perfusion on Postvasectomy Azoospermia
}

\author{
Brian Eisner, $M D^{1}$ \\ Timotby Schuster, $M D^{1}$ \\ Pbillip Rodgers, $M D^{2}$ \\ Muzammil Abmed, $M D^{1}$ \\ Gary Faerber, $M D^{1}$ \\ Gary Smith, $P b D^{3}$ \\ Dana Obl, $M D^{1}$
}

'Department of Urology, University of Michigan, Arbor, Mich

${ }^{2}$ Department of Family Medicine, University of Michigan, Ann Arbor, Mich

${ }^{3}$ Departments of Urology, Obstetrics/ Gynecology, and Physiology, University of Michigan, Ann Arbor, Mich

Conflicts of interest: none reported

\section{CORRESPONDING AUTHOR:}

Timothy G. Schuster, MD

Department of Urology

University of Michigan

2917 Taubman Center 0330

1500 E Medical Center Dr

Ann Arbor, MI 48109-0330

tgschust@umich.edu

\begin{abstract}
BACKGROUND We wanted to determine whether a saline flush during vasectomy would reduce the time needed to reach azoospermia.

METHODS During vasectomy men were randomly assigned to flush the prostatic end of the vas deferens with $10 \mathrm{~mL}$ of normal saline (intervention group, $\mathrm{n}=$ $50)$, while the remaining men $(n=56)$ served as controls. Sperm counts were performed on the immediate postprocedure urine specimen and on semen samples at 1,6 , and 12 weeks after vasectomy.
\end{abstract}

RESULTS The postprocedure urine specimens from the intervention and control groups contained $29.2 \times 106$ and 0.004 × 106 sperm, respectively $(P<.001)$. Total sperm counts in the ejaculate for intervention and control groups at 1,6 , and 12 weeks were (in millions of sperm): 14.1 and $13.8,0.4$ and 8.0 , and 0.0 and 0.011 , respectively $(P>.05$ at all time points). There was no difference in the rate at which the men in the 2 groups achieved azoospermia.

CONCLUSIONS Vasal perfusion with saline during vasectomy was effective in removing sperm from the distal vas; however, perfusion did not increase the rate at which men achieve azoospermia.

Ann Fam Med 2004;2:221-223. DOI: 10.1370/afm.59.

\section{INTRODUCTION}

$\mathrm{V}$ asectomy continues to be the most reliable form of male contraception worldwide. Nearly 42 million couples rely on vasectomy as their method of family planning. ${ }^{1}$ Previous reports suggest that the failure rate of vasectomy is $0.0 \%$ to $0.08 \%{ }^{2-4}$ Even so, the desired endpoint of azoospermia is not achieved immediately after surgery. It is widely accepted in clinical practice that becoming azoospermic may take up to 4 months for most men because of sperm residing in the seminal vesicles and vas deferens upstream from the surgical incision. ${ }^{5}$

Some investigators have suggested that the number of ejaculates after surgery can shorten the time to azoospermia. ${ }^{6,7}$ Others, however, have shown that coital frequency alone does not necessarily improve the time to clearance of sperm after vasectomy. ${ }^{8}$

We hypothesized that flushing the prostatic end of the vas deferens with saline might shorten the time needed to reach azoospermia. Although previous studies have examined the role of vas irrigation at the time of surgery, many have lacked randomization, had poor postoperative compliance, or included as success the presence of nonmotile sperm in the ejaculate after vasectomy. The purpose of the this study was to examine the effect of intraoperative irrigation of the vas deferens on the semen counts after vasectomy, with special regard to the time needed to reach azoospermia. 


\section{METHODS}

Institutional Review Board approval was obtained for the study. One hundred six subjects were randomized into either perfusion (intervention group) or nonperfusion (control group). All men underwent a no-scalpel vasectomy as described by Li et al. ${ }^{9}$ Briefly, the surgery included removal of 1 to $2 \mathrm{~cm}$ of each vas deferens and then intraluminal diathermy to cauterize both the testicular and prostatic free ends of the vas. In addition, patients in the intervention group underwent perfusion of the prostatic free end with $10 \mathrm{~mL}$ of normal saline on each side before cauterization. For all subjects, suture ligatures were applied to the testicular ends of the vas as part of our standard procedure. All vasectomies were performed on an outpatient basis under local anesthesia. After randomization, neither patients nor physicians were blinded to the treatment arm.

A urine specimen was collected from all patients immediately after the vasectomy and analyzed for the presence of spermatozoa. If sperm were seen in the postprocedure urine, a quantitative count was performed. Semen specimens were examined at 1, 6, and 12 weeks after vasectomy, and quantitative sperm counts were performed on each occasion. Azoospermia was defined as the total absence of sperm from the ejaculate. Differences in sperm counts between the 2 groups were compared using the Mann-Whitney rank sum test. Differences in the percentages of men in each group who achieved azoospermia were compared using the log-rank test. The study had a power of $80 \%$ to detect a difference of $16 \%$ in the proportion of men achieving azoospermia.

\section{RESULTS}

The mean age of men in the intervention group (36 years old; range $27-58$ years) was not significantly different from that of the men in the control group (37 years old $i$ range $24-48$ years) $(P>.05$, Student $t$ test $)$.

The findings, displayed in Table 1 , show lower sperm counts for the control group in the urinalysis immediately after vasectomy, but there were no significant differences in sperm counts between the 2 groups at 1,6 , and 12 weeks.

The number (percentage) of patients who had achieved azoospermia in perfusion and control groups, respectively, were as follows: at 1 week, 21/50 (27.5\%) compared with 24/56 (31.9\%); at 6 weeks, $45 / 50(90.0 \%)$ compared with $47 / 56(83.9 \%)$; at 12 weeks, 50/50 (100.0\%) compared with 53/56 (94.6\%). There was no difference between the 2 groups in the rate of achieving azoospermia at each point $(P>.05$, log-rank test).
Table 1. Mean Number of Sperm (in Millions) Found in Urine Samples and Semen Samples at 1, 6, and 12 Weeks After Vasectomy

\begin{tabular}{lccc}
\hline $\begin{array}{l}\text { Sampling } \\
\text { Period }\end{array}$ & $\begin{array}{c}\text { Intervention } \\
\text { Group }\end{array}$ & $\begin{array}{c}\text { Control } \\
\text { Group }\end{array}$ & $P$ Value \\
\hline $\begin{array}{l}\text { Urine sample after } \\
\text { vasectomy }\end{array}$ & 29.2 & 0.004 & $<.001$ \\
$\begin{array}{l}\text { 1-week semen sample } \\
\text { 6-week semen sample }\end{array}$ & 14.1 & 13.8 & $>.05$ \\
$\begin{array}{l}\text { 12-week semen sample } \\
\text { Note: Before cauterization, the prostatic end of the vas deferens was perfused } \\
\text { with 10 mL normal saline on each side for patients in the intervention group } \\
\text { (n }=50) \text {, while patients in the control group ( } n=56 \text { ) were not perfused. } \\
\text { Statistical analysis was performed using the Mann-Whitney test. }\end{array}$ \\
\hline
\end{tabular}

\section{DISCUSSION}

Previous investigators have performed vasectomy perfusion trials. Craft and McQueen, ${ }^{10}$ using sterile water for perfusion, showed that $6.3 \%$ of perfused patients and $25.5 \%$ of nonperfused patients had persistent sperm in the ejaculate at 15 weeks; however, the study was not randomized. Yu et a ${ }^{11}$ found no significant differences at 2 and 4 weeks after vasectomy when flushing with sterile water, but did note that 28\% (perfused) and 59\% (nonperfused) of patients had sperm in the ejaculate at 6 weeks. The definition of success, however, included men with nonmotile spermatozoa (see below). Berthelsen, ${ }^{12}$ also using sterile water for perfusion, noted no difference in time to azoospermia between the perfused and nonperfused groups, but of 59 patients randomized at the time of vasectomy, only $38(64 \%)$ completed their follow-up semen checks. Similarly, Mason et a ${ }^{13}$ randomized 200 patients using sterile water for perfusion of the vas deferens. Of the 163 patients ( $82 \%$ ) with follow-up information, no difference in time to azoospermia was noted between the 2 groups.

Other investigators have studied the effectiveness of perfusing the vas with spermicidal compounds during vasectomy to rid the distal duct of motile sperm. ${ }^{14-17}$ These investigators, as did Yu et al, ${ }^{11}$ assumed that nonmotile sperm will not cause a pregnancy, which is a standard that can be questioned.

In their review of the literature, Mumford and Davis $^{18}$ note that the collected results of the aforementioned studies are equivocal and do not clearly show whether perioperative flushing reduces the time required to reach azoospermia after vasectomy. In particular, discrepancies exist among published trials with regard to the definition of azoospermia. Many of the studies reviewed by Mumford and Davis used the absence of motile sperm from the ejaculate as their desired endpoint, allowing the presence of only nonmotile sperm to be sufficient evidence of adequate 
contraception. ${ }^{10,11,14,19-21}$ It should be noted, however, that nonmotile sperm in the ejaculate in the first few weeks after vasectomy can be an indication of early recanalization of the vas deferens. ${ }^{22}$ Furthermore, Thomson et $\mathrm{al}^{23}$ reported a case in which a seemingly infertile male with only nonmotile sperm impregnated his wife.

Our investigation was randomized, with all consecutive vasectomy patients offered entry into the study. Compliance in follow-up semen specimens was $100 \%$. The study had sufficient power to detect a clinically meaningful difference. Given the great number of patients that would need to be treated to achieve earlier azoospermia in only a small number of patients, we do not believe vas perfusion in practice is justified.

In our study, intraoperative saline perfusion was highly effective in removing sperm from the distal vas deferens, as evidenced by the difference in the total sperm numbers in the urine immediately after vasectomy between the two groups. Despite this finding, irrigation did not change the mean sperm numbers in the ejaculate samples of either group at 1,6 , or 12 weeks, nor did it decrease the time required to achieve azoospermia. The residual sperm seen in semen checks after successful vasectomy may reside in the seminal vesicles, where their anatomic location is not affected by perfusion through the vas deferens alone. Because sperm stored in the seminal vesicle are typically nonmotile as a result of its toxic environment, ${ }^{24}$ and because nearly all sperm seen after a successful vasectomy are nonmotile (until azoospermia is observed), this theory seems quite plausible.

This study has limitations that could be evaluated in future studies. We did not give specific instructions to patients regarding frequency of ejaculation after vasectomy, nor did we record this information from patients. As mentioned, these factors may have an additional impact on time to achieve azoospermia.

To read or post commentaries in response to this article, see it online at http://www.annfammed.org/cgi/content/full/2/3/221.

Key words: Vasectomy; vas deferens; azoospermia; sterilization, reproductive system; reproductive and urinary physiology; irrigation

Submitted December 6, 2002; submitted, revised, March 21, 2003; accepted May 26, 2003.

\section{References}

1. Haldar N, Cranston D, MacKenzie I, Guillebaud J. How reliable is a vasectomy? Long-term follow-up of vasectomised men. Lancet. 2001;356:43-44.

2. Schmidt SS. Vasectomy. Urol Clin North Am. 1987;14:149-154.

3. Alderman PM. The lurking sperm: a review of failures in 8879 vasectomies performed by one physician. JAMA. 1988;259:3142-3144.

4. Philp T, Guillebaud J, Budd D. Complications of vasectomy: review of 16,000 patients. Br J Urol. 1984;56:745-748.

5. Belker AM, Sexter MS, Sweitzer SJ, Raff MJ. The high rate of noncompliance for post-vasectomy semen examination: medical and legal considerations. J Urol. 1990;144:284-286.

6. Freund M, Davis JE. Disappearance rate of spermatozoa from the ejaculate following vasectomy. Fertil Steril. 1969;20:163-170.

7. Schmidt SS. Vasectomy by section, luminal fulguration and fascial interposition: results from 6248 cases. Br J Urol. 1995;76:373-375.

8. Marwood RP, Beral V. Disappearance of spermatozoa from ejaculate after vasectomy. Brit Med J. 1979;1;87.

9. Li SQ, Goldstein M, Zhu J, Huber D. The no-scalpel vasectomy. J Urol. 1991;145:341-344.

10. Craft I, McQueen J. Effect of irrigation of the vas on post-vasectomy semen-counts. Lancet. 1972;1:515-516.

11. Yu HYH, Halim A, Evans PR. Clorhexidine for irrigation of vas: a clinical trial and the study of viability of non-motile sperms in post-vasectomy patients with trypan blue uptake. Br J Urol. 1976;8:371-375.

12. Berthelsen JG. Perioperative irrigation of the vas deferens during vasectomy. Scand J Urol Nephrol. 1976;10:100-102.

13. Mason RG, Dodds L, Swami SK. Sterile water irrigation of the distal vas deferens at vasectomy: does it accelerate clearance of sperm? A prospective randomized trial. Urology. 2002;59:424-427.

14. Edwards I. Vasectomy: irrigation with euflavine. Med J Aust. 1977;1: 847-849.

15. Urquhart-Hay D. Immediate sterility after vasectomy. N Z Med J. 1975;531:11-12.

16. Albert PS, Seebode J. Nitrofurazone: vas sterilization as adjunct in vasectomy. Urology. 1977; 10:450-451.

17. Slome J. Irrigation of the vas for immediate sterility after vasectomy [letter]. Br Med J. 1975;4:649.

18. Mumford SD, Davis JE. Flushing of the distal vas during vasectomy: current status and review of the literature. Urology. 1979;14:433-441.

19. Gandrup P, Berthelsen JG, Nielsen OS. Irrigation during vasectomy: a comparison between sterile water and the spermicide euflavine. J Urol. 1982;127:60-61.

20. Hamilton DW. Immediate sterility after vasectomy. Med J Aust. 1977;1:402-403.

21. Lehtonen T. Effect of irrigation of vas deferens on sperm analyses after vasectomy. Ann Chir Gynaec Fenn. 1975;64:224-226.

22. Esho JO, Ireland GW, Cass AS. Recanalization following vasectomy. Urology. 1974;3:211-214.

23. Thomson JA, Lincoln PJ, Mortimer P. Paternity by a seemingly infertile vasectomised man. BMJ. 1993;307:299-300.

24. OhI DA, Menge AC, Jarow JP. Seminal vesicle aspiration in spinal cord injured men: insight into poor sperm quality. J Urol. 1999;162: 2048-2051. 